\section{How could Archeo-Geophysics help garbage disposal? A fortuitous discovery in Central Italy}

\author{
Pier Matteo Barone, Carlotta Ferrara, \\ Elena Pettinelli \\ Department of Physics, University of \\ Roma Tre, Italy
}

\begin{abstract}
We present a non-destructive geophysical technique (Ground Penetrating Radar) as a suitable method for both the detection of buried archeological structures, as is already known, and as an aid to local administrators in the planning of potential waste management sites (e.g., landfills or incinerators). This can prevent the potential destruction of important archeological sites. The discovery of a subsurface archeological target a few dozen kilometers northeast of Rome, near the proposed site for the construction of a waste-to-energy incinerator, should cause local administrations to reconsider their plans for construction at this site.
\end{abstract}

\section{Introduction}

When Emperor Hadrian built his palace in Rome's countryside in the second century $\mathrm{AD}$, he wanted to escape the sounds and smells of the capital city. Now, 18 centuries later, the unpleasant smells of the city may follow him there via an emergency landfill built near his villa due to a lack of landfill space closer to Rome. ${ }^{1}$

This has been a highly publicized waste management issue in Central Italy over the last several months, but fortunately the local administration decided to abandon this landfill project. However, there is another proposed landfill a few dozen kilometers northeast of Rome in the Rieti Province. The proposed incinerator will be located near Santa Rufina-Cittaducale and will create many archeological problems during its construction and operation, as well as geological problems due to the porous nature of the soil. ${ }^{2} \mathrm{~A}$ geo-morphological survey showed a large marnous limestone plain associated with the formation of Mount Reatini, covered by upper Pleistocene/ Holocene alluvial deposits. ${ }^{3,4}$

The archeological and preservation problems are linked to several archeological remains in the area, referred to as the Ager Sabinus (along the Salaria road). The Ager
Sabinus has prominent archeological remains: Roman baths (i.e., the Cotilia and Vespasian baths), the Trebula Mutuesca archeological site, the Bruttii Praesentes Roman villa, Roman walls and bridges, and many other sites whose cultural heritage has not been discovered throughout the province of Rieti. ${ }^{5}$ In particular, the area near the modern springs of Cotilia has undergone centuries of changes to utilize the thermal waters in the area. ${ }^{6}$

This area also presents many problems due to its geomorphology. The area is surrounded by several sinkholes (a natural depression in the earth's surface caused by karst processes and the chemical dissolution of carbonate rocks), sometimes producing $\mathrm{CO}_{2}$ gas vents. ${ }^{7}$

During the Geophysical response of a gas vent in a rural area one-day field school, organized by the Geophysics Laboratory of the Department of Physics at the University of Roma Tre, the participants acquired several non-destructive Ground Penetrating Radar (GPR) profiles to investigate the subsurface.

\section{Materials and Methods}

The aim of the GPR measurements was to locate, delineate, and understand a gas vent near Cotilia. Gas vents are typical to this area, which is rich in similar geo-morphologic features. The data were acquired using a bistatic Noggin Plus GPR system (Sensors \& Software, Inc., Mississauga, ON, Canada) equipped with $250-\mathrm{MHz}$ antennas. The study area is $25 \times 15 \mathrm{~m}$, with a multi-profile acquisition in one direction, a line spacing of $0.5 \mathrm{~m}$ (Figure 1), a stacking of 4 , a time window of $100 \mathrm{~ns}$, and a signal velocity of $0.085 \mathrm{~m} / \mathrm{ns}$, estimated using the hyperbolic calibration method. ${ }^{8}$

Due to the aim of the GPR survey, the study area is small, but it is within the area of the proposed waste-to-energy incinerator.

GPR is a geophysical method that uses electromagnetic waves, typically in the frequency range of $10-3000 \mathrm{MHz}$, to image subsurface structures. The physical basis of GPR detection is the dielectric contrast between the buried target and the background material. Such a contrast can be produced in several ways: by spatial changes in the physicalchemical properties of the sediments or the soil, by changes in the water content and bulk density of the material, or by the presence of different objects in the subsoil, such as voids, rock boulders, wood, metal, or plastic. In general, strong signal reflections on a GPR image are generated if there is a detectable dielectric contrast between subsurface objects. ${ }^{8,9}$
Correspondence: Pier Matteo Barone, Department of Physics, University of Roma Tre, via della Vasca Navale, 84 - 00146 Rome, Italy.

E-mail: pmbarone@fis.uniroma3.it

Key words: archeology, GPR, incinerator, preser vation.

Contributions: the authors contributed equally.

Received for publication: 24 April 2012.

Revision received: 27 July 2012 .

Accepted for publication: 6 August 2012.

This work is licensed under a Creative Commons Attribution 3.0 License (by-nc 3.0).

(C) Copyright P.M. Barone et al., 2012

Licensee PAGEPress, Italy

Antiqua 2012; 2:e3

doi:10.4081/antiqua.2012.e3

GPR systems consist of four main elements: a transmitting unit, a receiving unit, a control unit, and a display unit [Digital Video Logger (DVL)]. The transmitter produces a short-duration, high-voltage pulse. This pulse is applied to the transmitting antenna (Tx), which radiates the pulse into the ground. The receiving antenna ( $\mathrm{Rx})$ collects the signals after they have traveled through the subsurface. The signals are amplified and formatted for display by the DVL, as depicted in Figure 2.

The radar measures the signal amplitude through time (two-way travel time) for each Tx-Rx configuration on the ground. The data are collected by moving the Tx-Rx system along a profile. This produces a two-dimensional (2D) radar cross-section containing the two-way travel time along the Y-axis and the position of the antenna along the $\mathrm{X}$-axis for each profile. To estimate the depth of the target (i.e., to convert time into depth), a simple calibration technique can be used, ${ }^{8}$ although more refined algorithms should be applied for complicated subsurface scenarios. ${ }^{8,9}$ The velocity and attenuation of the radar signals depend on the electromagnetic properties of the soil, which may be frequency-dependent. In particular, the maximum depth of investigation decreases rapidly with increasing frequency in most geomaterials due to attenuation. Thus, most subsurface radar systems operate at frequencies less than $3 \mathrm{GHz}$. The antenna frequency also affects the vertical and horizontal resolution in a GPR image; resolution increases with increasing antenna frequency.

To obtain an XY image (i.e. map) of the subsurface, the radar data should be collected in multi-profile mode, in which parallel profiles are acquired at a fixed separation. This technique allows one to create a $\mathrm{XY}$ 
time (or depth) maps that can be used to identify targets and their geometries (2D reconstruction). ${ }^{10}$

\section{Results}

A deeper unexpected geophysical anomaly was found beneath the gas vent.

Generally, the GPR data had high vertical and horizontal resolutions, and no particular filtering or amplitude increases were necessary other than the defaults (Dewow and Automatic). During data processing, depthslice maps are created through 2D reconstruction using the average envelope amplitude technique. This reveals anomalies that are likely due to man-made structures (Figure 3A). Two types of anomalies are observed in our data: a large rectangular anomaly and a strong reflector. As shown in Figure $3 \mathrm{~B}$, the main rectangular anomaly in the radar image could be interpreted as a plane associated with a Roman thermal system associated with geometric remains of brick walls, as has been described in the literature. ${ }^{11}$ The strong reflector in the northeast corner of the survey area has a high reflection coefficient and could be interpreted as the remains of an ancient road based on its dimensions and shape. This explanation is confirmed by analyzing the radar cross section (Figure 3C) and a schematic reconstruction of a Roman road (Figure 3D), where the two umbones (Latin for large vertical stones delimiting the road) and the dorsum (Latin for the paving stones) are easily detected.

\section{Conclusions}

These results confirm the archeological potential of this area and show how GPS can be used to non-invasively detect buried archeological targets. Moreover, this approach demonstrates the risk introduced by building an incinerator in this area, for both the cultural heritage and subsurface archeological and geomorphic structures. By using GPR imaging, garbage disposal sites can be planned more wisely. The local administration should base waste management decisions on landscape analysis using this type of non-destructive geophysical technique, which also could be applied to other proposed developments in this area.

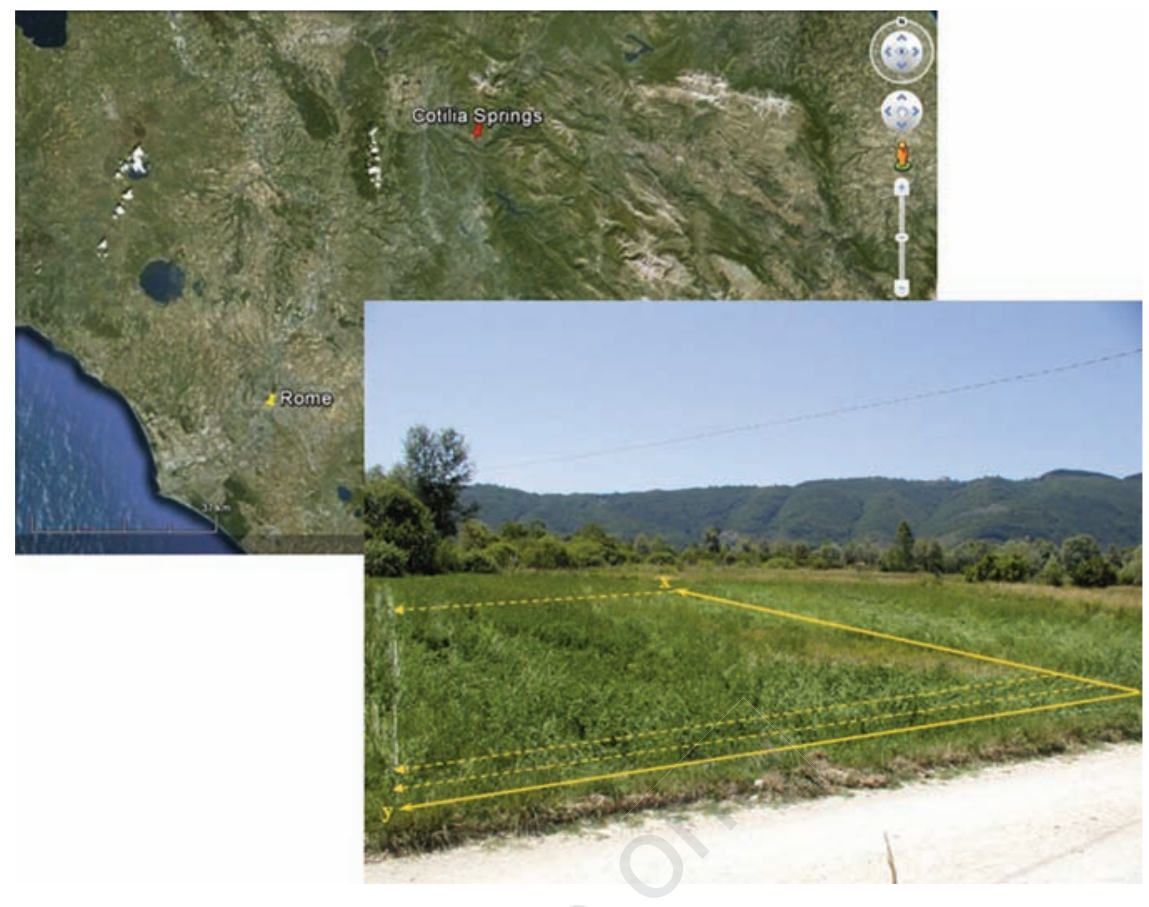

Figure 1. Above: a map showing Rome and the study area (Cotilia Springs); below: a reconstruction of the Ground Penetrating Radar survey.

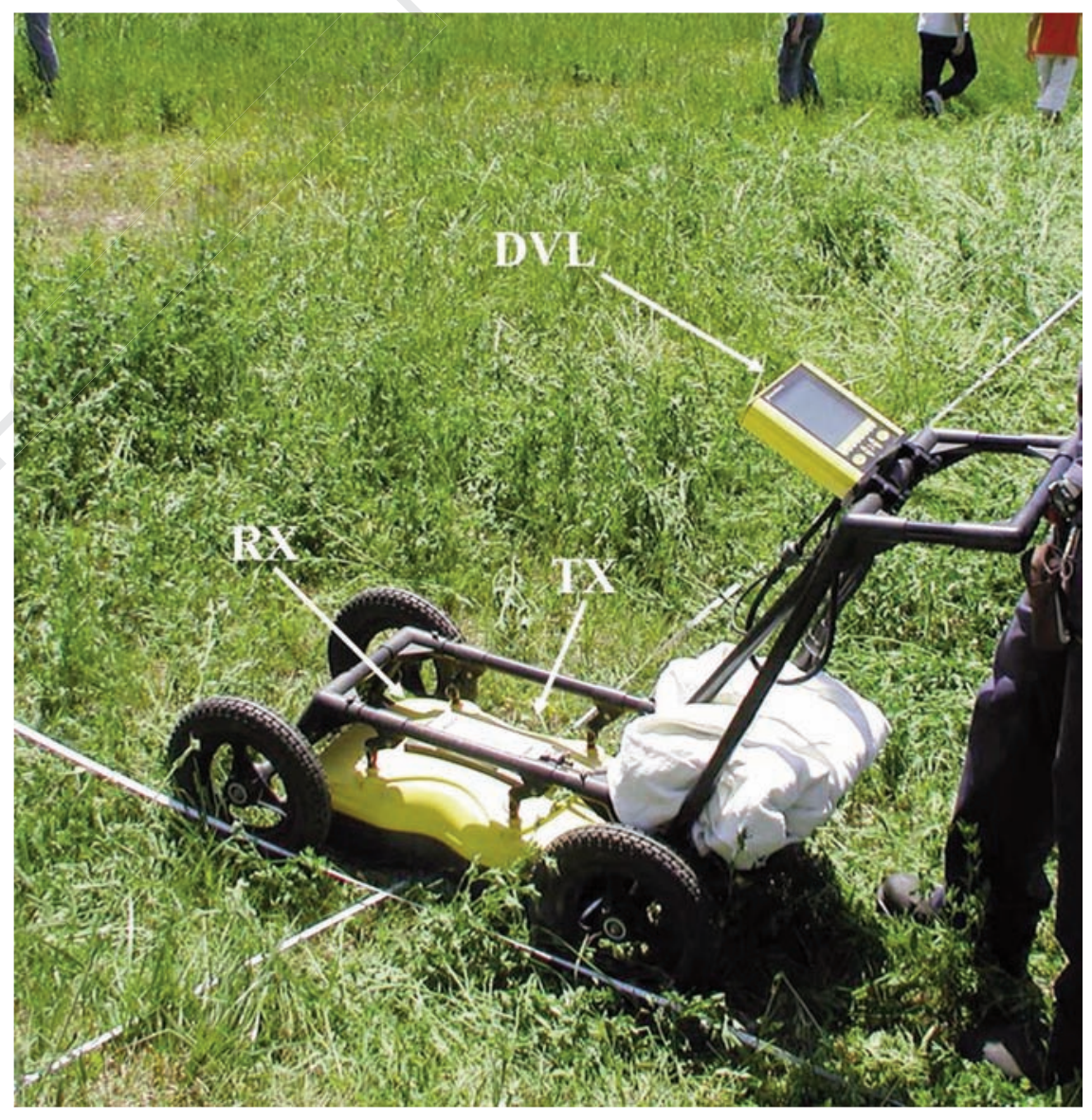

Figure 2. The Ground Penetrating Radar system used during the survey: a Noggin Plus bistatic system with $250-\mathrm{MHz}$ transmitter $(\mathrm{Tx})$ and receiver $(\mathrm{Rx})$ antennas and a Digital Video Logger (DVL) to check the data acquisition in real-time. 


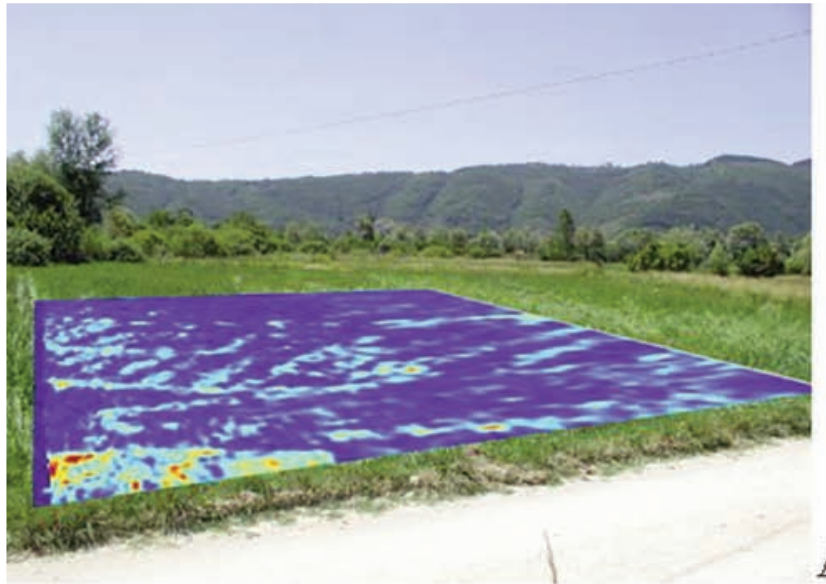

A

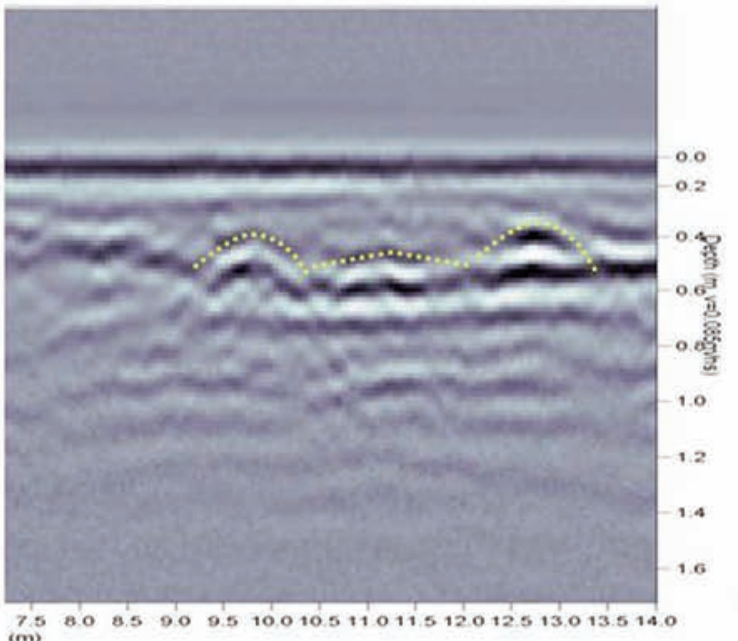

m

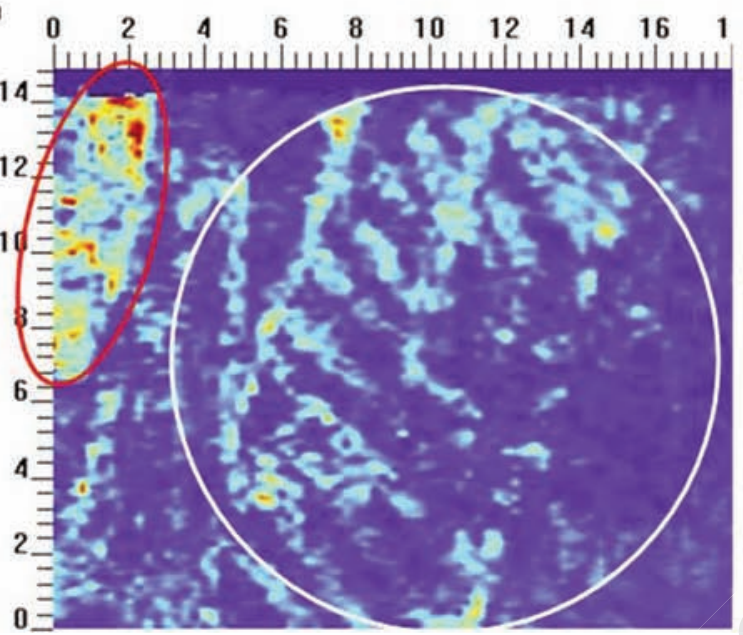

Figure 3. The Ground Penetrating Radar results overlain on the survey area (3A): the white circle highlights a likely a thermal geometric structure and the red circle highlights an ancient road (3B). The second anomaly is also clearly visible in the radar cross section (3C) and the schematic reconstruction $(3 \mathrm{D})$.

\section{References}

1. Kington T. Noble defends Hadrian's villa from Rome's rubbish. The Guardian. 2011 Nov 1; http://www.guardian.co.uk

2. Boni C, Bono P, Capelli G. Carta idrogeologica del territorio della Regione Lazio. Scala 1:250.000. Regione Lazio: 1988.

3. Centamore E, Nisio S. Quaternary morfodinamic between the Velino and Salto Valleys. Camerino: Studi Geol. Camerti, Vol Spec.; 1999. pp 37-44.

4. Faccenna C, Florindo F, Funiciello R, Lombardi S. Tectonic setting and Sinkhole
Features: case histories from western Central Italy. Quat Proc 1993;3:47-56.

5. Maetzke G, (ed). Identità e civiltà dei Sabini. Firenze: L.S. Olschki Editore; 1996.

6. Leggio T. Da Cures Sabini all'Abbazia di Farfa. Trasformazioni del paesaggio tra Tevere, Corese e Farfa dall'età romana al medioevo. Passo Corese: Banca Popolare di Rieti; 1992.

7. Petitta M, Primavera P, Tuccimei P, Aravena R. Interaction between deep and shallow groundwater systems in areas affected by Quaternary tectonics (Central Italy): a geochemical and isotope approach. Envir Earth Sci 2011;63:11-30.
8. Annan PA. Ground penetrating radar: principles, procedures and applications. Mississauga ON: Sensors \& Software Inc.; 2004.

9. Jol HM. Ground penetrating radar: theory and applications. Elsevier: Oxford; 2009.

10. Pettinelli E, Barone PM, Di Matteo A, et al. Mapping the undiscovered ruins of Pompeii (Naples, Italy) using Ground Penetrating Radar. Archaeometry 2012; 54:203-12.

11. Finzi E, Praticelli N, Vettore L, Zaja A. Multi-temporal geophysical survey of a Roman Bath complex in Montegrotto Terme (Padova, Northern Italy). Archaeol Prospect 2007;14:182-90. 
